\title{
Process variable optimization in the cold metal transfer weld repair of aerospace ZE41A-T5 alloy using central composite design
}

\author{
O. T. Ola ${ }^{1} \cdot$ R. L. Valdez ${ }^{1} \cdot$ K. M. Oluwasegun ${ }^{2} \cdot$ O. A. Ojo ${ }^{2} \cdot$ K. Chan $^{3} \cdot$ A. Birur ${ }^{4} \cdot$ J. Cuddy $^{4}$
}

Received: 3 July 2019 / Accepted: 17 October 2019/Published online: 16 November 2019

(C) The Author(s) 2019

\begin{abstract}
The pulsed cold metal transfer $(\mathrm{CMT}+\mathrm{P})$ process was evaluated for the repair of aerospace structural components made from ZE41A-T5 magnesium alloy. The choice of welding variables was considered to be unique for the material type, weld design and geometry, and application-specific requirements. A design of experiment (DOE) method based on a rotatable 3D central composite design (CCD) was used to systematically establish relationships between independent welding variables and the resultant output variables of the CMT+P process, including the development of mathematical models based on second-order polynomial. A multiple response desirability function approach was then used for process optimization. The CMT+P process produced highquality welds in the alloy. Welding process variables were established to produce desired weld penetration and weld reinforcement and complete fusion with minimal weld defects. Optimal domains of the independent variables were achieved; where the welds comply with the application-specific (repair of gearbox housing) requirements and acceptable class A weld quality of the aerospace fusion welding standard AWS D17.1.
\end{abstract}

Keywords Cold metal transfer $\cdot$ Magnesium alloys $\cdot$ Aerospace $\cdot$ Design of experiment $\cdot$ Process optimization $\cdot$ Welding

\section{Introduction}

Magnesium (Mg) alloys are used for selected aerospace structural applications due to their specific strength [1-3]. The manufacturing, maintenance, and repair of components made from $\mathrm{Mg}$ alloys require the use of welding processes that maximize strength at low structural distortion. Unfortunately, the repair of $\mathrm{Mg}$ alloys using conventional welding processes (tungsten inert gas welding (TIG) and gas metal arc welding (GMAW)) is very challenging. Mg alloys possess physical properties that make them highly susceptible to the formation of weld defects and oxides and excessive geometrical

O. T. Ola

oola@ rrc.ca

1 Technology Access Centre for Aerospace and Manufacturing, Red River College of Applied Arts, Science and Technology, Winnipeg, Manitoba, Canada

2 Department of Mechanical Engineering, University of Manitoba, Winnipeg, Manitoba, Canada

3 Huys Industries, Toronto, Ontario, Canada

4 Standard Aero Limited, Winnipeg, Manitoba, Canada distortion, which become detrimental to the quality of welds produced. In addition, conventional welding processes do not offer sufficient repeatability, post-weld strength, or control of distortion to meet stringent aerospace acceptance standards with minimal post-weld heat treatment. Consequently, weld behavior studies in aerospace $\mathrm{Mg}$ alloys continue to be a subject of rigorous research.

Fronius developed a relatively new and advanced fusion welding technology - cold metal transfer (CMT) - as a revolutionary alternative to the conventional welding technologies. The CMT technology is a digital, microprocessorcontrolled welding process that differs from the traditional GMAW by using electrode short circuit and precise control of filler wire for material transfer. Lorenzin and Rutili [4] provided some description of the operating principle, advantages, limitations, and some applications of the CMT process. The characteristics of the CMT process for cladding aluminum alloy 2024 were reported by Picking et al. [5]. Arc characteristics during dissimilar welding of aluminum to zinccoated steel were studied and reported by Zhang et al. [6]. Egerland and Helmholdt [7] discussed some benefits of using CMT for overlaying components of waste incinerators. Wang et al. [8] discussed some aspects of microstructural developments in Al-Mg dissimilar CMT welds. Mechanical and 
microstructural characteristics of CMT welds in 6061 aluminum during post-weld heat treatment were also studied [9]. The CMT process was evaluated and used for dissimilar joining and weld brazing of pure titanium to an $\mathrm{Mg}$ alloy [10]. In addition, the CMT process has been considered as an additive manufacturing variant that is based on arc wire technology [11-14]. The CMT process is particularly known for the production of low heat input welds and low dilution of filler materials with the base alloy, with advantages including low structural distortion and low residual stresses.

In CMT welding, a molten droplet is produced on the end of the filler wire during the arcing phase. After a predetermined duration of time, the filler wire electrode is fed forward such that the molten droplet is caused to make contact with the base alloy, resulting in a short circuit that shortly extinguishes the arc. After a set time lapse, the filler wire electrode is caused to mechanically retract, thereby leaving the molten droplet in the weld pool. Material transfer occurs at significantly low current and voltage values (low power) due to the short circuit. The arc reignites during the rearward motion of the filler wire electrode. This cycle repeats approximately every $11 \mathrm{~ms}$ in the standard CMT process.

Although the CMT technology revolutionized how fusion welding is done, process development will continue to be material- and application-dependent. The choice of welding variables is unique for material types and sizes, weld design and geometry, and other application-specific requirements. Therefore, selection of welding variables for process development and optimization must be done using a proven and reliable method. Design of experiment (DOE) provides a scientific/statistical approach for evaluating process variables. Many DOE methods are based on the full factorial design, which is not developed to account for the effects of curvature [15-17]. However, DOE methods that account for linear, interaction, and quadratic effects are more accurate and more desirable. DOE methods that account for response surfaces as part of the initial design have an advantage of possible reduction in the number of experiments required for establishing relationships between input and output parameters $[18,19]$.

In addition to interaction and quadratic effects, the ultimate goal of DOE is not limited to understanding relationships between variables but progressing toward process optimization. Suthkar et al. [20] studied the relationships between laser welding input parameters (laser power density, welding speed, beam angle, and shielding gas flow rate) and output variables (bead width, weld penetration, and aspect ratio). They used a response surface methodology to predict limits of welding process parameters. Wang et al. [21] discussed an approach for multiresponse optimization with considerations for the robustness of the variables. Kim and Lee [22] used gray relational approach to optimize welding parameters for laser-arc hybrid welding of an aluminum alloy and compared their results with those obtained from Taguchi methods. The current authors and other researchers have also used artificial neural network models for predicting output parameters during welding processes [23, 24]. Nevertheless, a method combining DOE with a multiresponse process optimization [25] provides a gateway for an efficient and reliable solution to optimization problems.

In this present work, a design of experiment (DOE) method based on a rotatable 3D central composite design (CCD) was used to systematically establish relationships between independent welding variables and the resultant output variables of the pulsed CMT $(\mathrm{CMT}+\mathrm{P})$ process. A multiple response desirability function approach was then used for process optimization. This work has a specific application in the use of the CMT welding process for the repair of gearbox housing made from $\mathrm{Mg}$ alloy ZE41A-T5. A detailed discussion on the research methodology and the results are provided in this manuscript.

\section{Material and methods}

\subsection{Materials preparation and CMT welding}

Cast Mg alloy ZE41 with a nominal composition of (weight percent) $4.3 \mathrm{Zn}, 0.8 \mathrm{Zr}$, 0.7 Ce, 1.2 RE (rare earth elements), and balance $\mathrm{Mg}$ was received in the artificially aged $\mathrm{T} 5$ condition. The materials were machined into welding coupons having dimensions of $150 \mathrm{~mm} \times 50 \mathrm{~mm} \times 12.5 \mathrm{~mm}$. Grooves $10 \mathrm{~mm}$ wide and $1.8 \mathrm{~mm}$ deep were machined on the coupons. The welding filler used in this work was made of AZ61 alloy received in the form of cut length welding rods of $1.2 \mathrm{~mm}$ diameter. Welds were produced on the coupons using a robotic Fronius CMT welding system at the Centre for Aerospace Technology and Training (CATT), Winnipeg, Canada. The CMT welding system was automated by a 6axis Yaskawa Motoman robot and operated in the pulsed CMT (CMT+P) mode. The weld path and speed were controlled by the robot, while other welding parameters were controlled through the remote control unit (RCU) and the synergic lines of the CMT system. After welding, the coupons were sectioned transverse to the welding direction using a Hansvedt DS-2 traveling wire electrical discharge machine. Three sections were selected from each of the welding coupons and prepared using standard metallographic procedure (ASTM E3-11). Geometrical and microstructural characteristics of the welds were analyzed using a Nikon SMZ800 optical microscope and a Nikon Eclipse MA100 inverted optical microscope both equipped with NIS Element D imaging software. 


\subsection{The central composite design}

DOE was used to systematically establish relationships between welding parameters (independent variable or factors) and the output parameters (dependent or response variables) of the CMT+P process. For a set of measurable and controllable independent variables $x_{i}$, the response variable $Y$ can be expressed as:

$Y=f\left(x_{1}, x_{2}, x_{3}, \ldots \ldots \ldots, x_{k}\right)$

The DOE approach used for this work includes a rotatable central composite design (CCD). Each CCD consists of a minimum of 20 experimental runs with factors varying up to 5 levels. There were 8 corner points and 6 center points. The 3D design space for the 3 -factor CCD is shown in Fig. 1.

$\alpha=\left[2^{k}\right]^{1 / 4}$

where $k$ is the number of factors. For the 3 -factor CCD, $\alpha=$ 1.682 .

Table 1 contains the independent variables (factors) - travel speed, $v$; wire feed rate, $r$; and the pulse correction factor, $p c$. Both the coded and actual levels for the factors are presented in the table. The full design table is presented in Section 3.

Mathematical models based on second-order polynomial were developed for predicting the responses. The models are of the form

$Y=\beta_{0}+\sum_{i=1}^{k} \beta_{i} x_{i}+\sum_{i=1}^{k} \beta_{i i} x_{i}^{2}+\sum_{i} \sum_{j} \beta_{i j} x_{i} x_{j}+\varepsilon$

where $\beta_{0}$ is constant and $\beta_{i}, \beta_{i i}$, and $\beta_{i j}$ are linear, quadratic, and interaction coefficients, respectively. $\varepsilon$ is the residual

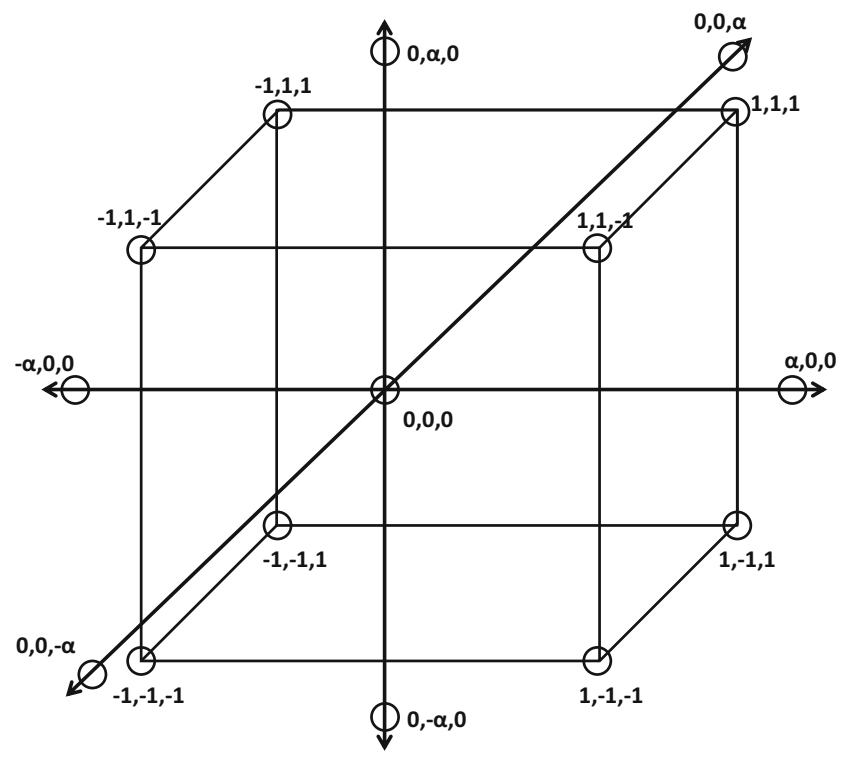

Fig. 1 The design space for the 5-level central composite design
Table 1 Variables and levels for the $\mathrm{CMT}+\mathrm{P}$ process

\begin{tabular}{lllllllll}
\hline Variable & Notation & Unit & \multicolumn{2}{l}{ Levels } & & & \\
\cline { 3 - 8 } & & & & -1.682 & -1 & 0 & 1 & 1.682 \\
\hline Travel speed & $v$ & $\mathrm{~mm} / \mathrm{s}$ & 7.0 & 9.6 & 13.5 & 17.4 & 20.0 \\
Wire feed rate & $r$ & $\mathrm{~m} / \mathrm{min}$ & 8.0 & 9.6 & 12.0 & 14.4 & 16.0 \\
Pulse corr. factor & $p c$ & None & -5 & -3 & 0 & 3 & 5 \\
\hline
\end{tabular}

error. The DOE and statistical analysis including analysis of variance (ANOVA), response surface plots, and regression analysis were carried out using Minitab 17 statistical analysis software.

\subsection{Approach for process optimization}

Process optimization was conducted using the desirability function approach. In this approach, each response, $Y_{i}$, is transformed to a desirability function, $d_{i}$, using a set of conditions. The function $d_{i}$ was defined such that

$0 \leq d_{i} \leq 1$

An increasing value of $d_{i}$ implies an increasing value of the desirability of the corresponding response $Y_{i}$. In order to maximize the overall desirability for multiple responses, the geometric mean of $d_{i}$ was calculated using

$D=\left(\prod_{i=1}^{n} d_{i}\right)^{1 / n}$

where $n$ is the number of responses. The conditions for determining $d_{i}$ are defined as follows, where $L_{i}$ and $U_{i}$ are the lower and upper specification limits, respectively, and $T_{i}$ is the target value. $w$ is the weight of the individual desirability function, which was taken as 1 in this work.

Case 1. Larger value of $Y_{i}$ is desired: In this case, the target $T_{i}$ is a maximum value.

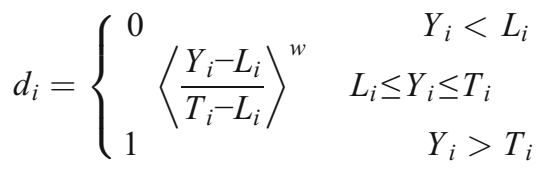

Case 2. Lower value of $Y_{i}$ is desired: $T_{i}$ is a minimum value.

$d_{i}=\left\{\begin{array}{lr}1 & Y_{i}<T_{i} \\ \left\langle\frac{U_{i}-Y_{i}}{U_{i}-T_{i}}\right\rangle^{w} & T_{i} \leq Y_{i} \leq U_{i} \\ 0 & Y_{i}>U_{i} .\end{array}\right.$

Case 3. $Y_{i}$ should be as close as possible to the target: $T_{i}$ is somewhere between $L_{i}$ and $U_{i}$. 


$$
d_{i}=\left\{\begin{array}{rr}
0 & Y_{i}<L_{i} \\
\left\langle\frac{Y_{i}-L_{i}}{T_{i}-L_{i}}\right\rangle^{w} & L_{i} \leq Y_{i} \leq T_{i} \\
\left\langle\frac{U_{i}-Y_{i}}{U_{i}-T_{i}}\right\rangle^{w} & T_{i} \leq Y_{i} \leq U_{i} \\
0 & Y_{i}>U_{i}
\end{array}\right.
$$

The desirability function $d_{i}$ and the overall desirability $D$ were calculated for the experiments. Up to 10 possible solutions of the optimized parameters were generated, and the best set of solutions was selected. Minitab 17 statistical analysis software was used. The responses studied and optimized in this work include the specified penetration depth for the aerospace application of interest (repair of gear box housing) and the level of underfill based on the welding standard AWS D17.1 specifically developed for fusion welding of aerospace alloys.

\section{Results and discussion}

\subsection{Overview of the $\mathrm{CMT}+\mathrm{P}$ welds}

In CMT welding, slower welding speed and higher wire feed speed have a general effect of increasing the amount of energy deposited per unit length of the weld. Higher wire feed speed (higher deposition rate) also provides more material for weld reinforcement. In the pulsed synergic CMT welding $(\mathrm{CMT}+\mathrm{P})$ mode used in this work, the pulse correction factor, $p c$, is usually used to influence droplet detachment force [26]. When the setting is at 0 , the droplet detachment force equals a value prepr ogrammed for the particular synergic line. In this case, the weld behavior is controlled by the wire feed speed and the welding (travel) speed in the absence of other forms of correction factors. Adjusting the pulse correction from -5 to +5 creates some deviation from the preprogrammed detachment force, where lower values result in higher pulse frequency, better wetting, and smaller droplets, while higher values result in lower pulse frequency, deeper penetration, and bigger droplets. In particular, less pulses per second (lower frequency), higher current, and higher droplet detachment force characterize +5 pulse correction, while more pulses per second (higher frequency), lower current, and lower droplet detachment force characterize -5 pulse correction.

Figure $2 \mathrm{a}$ and $\mathrm{b}$ show CMT+P welds in the ZE41A-T5 alloy. These welds were made with welding (travel) speed of $9.6 \mathrm{~mm} / \mathrm{s}$ and $13.5 \mathrm{~mm} / \mathrm{s}$, wire feed speed of $14.4 \mathrm{~m} /$ min and $12.0 \mathrm{~m} / \mathrm{min}$, and pulse correction factor of -3 and -5 , respectively. While the weld in Fig. 2a showed a relatively deep penetration with substantial weld reinforcement and no visible weld defects (such as porosity, cracking, undercut, underfill, and lack of fusion), the weld in Fig. 2b was relatively shallow with an underfill clearly visible. The parameters used for the weld in Fig. 2a favor higher heat input, deeper penetration, better weld reinforcement, and complete fusion. The design table and the measured responses of the $\mathrm{CMT}+\mathrm{P}$ welding of the ZE41A-T5 alloy are presented in Table 2. Results from the DOE analysis of the process variables are discussed next.

\subsection{Mathematical models, analysis of variance (ANOVA), and response surfaces}

Mathematical models based on second-order polynomial and ANOVA were developed for the output (dependent) variables. As discussed earlier, the selected output variables studied and optimized in this work include the specified penetration depth, $Y_{1}$, for the aerospace application of interest (repair of gear box housing) and the level of underfill, $Y_{2}$, based on the aerospace fusion welding standard AWS D17.1. ANOVA for $Y_{1}$ and $Y_{2}$ are presented in Tables 3 and 4, respectively. In the ANOVA, $\mathrm{DF}$ is the degrees of freedom. SS is the sum of squares. The mean square, MS, is given by SS/DF. The ratio of the MS for the model and the residual (error) is given by the $F$ value. $P$ is the probability used to test the hypothesis at $95 \%$ confidence level. A value of $\mathrm{P}$ less than 0.05 would indicate that the factor or source (linear, quadratic, or interaction) is significant. The standard deviation of the error, $S$, and the coefficient of determination, $R^{2}$, are also provided. A significantly small value of $S$ indicates the extent to which the model fits experimental data. $R^{2}$ is a measure of the percentage of variability explained by the model and is given by

$R^{2}=\left(1-\frac{\text { Error SS }}{\text { Total SS }}\right) \times 100 \%$

where $R^{2}$ values closer to $100 \%$ are desirable.

DOE analysis of the results in Table 2 and ANOVA for $Y_{1}$ and $Y_{2}$ yield the final regression (Eqs. 7 and 8).

$$
\begin{aligned}
Y_{1}= & -0.24+0.085 v+0.378 r+0.597 p c-0.00408 v^{2} \\
& -0.00630 r^{2}-0.00830 p c^{2}-0.00077 v^{*} r \\
& -0.01229 v^{*} p c-0.0289 r^{*} p c
\end{aligned}
$$

$$
\begin{aligned}
Y_{2}= & 2.35-0.0178 v-0.348 r-0.0030 p c+0.00377 v^{2} \\
& +0.01470 r^{2} \\
& +0.00301 p c^{2}-0.00416 v^{*} r-0.00327 v^{*} p c \\
& +0.00284 r^{*} p c
\end{aligned}
$$



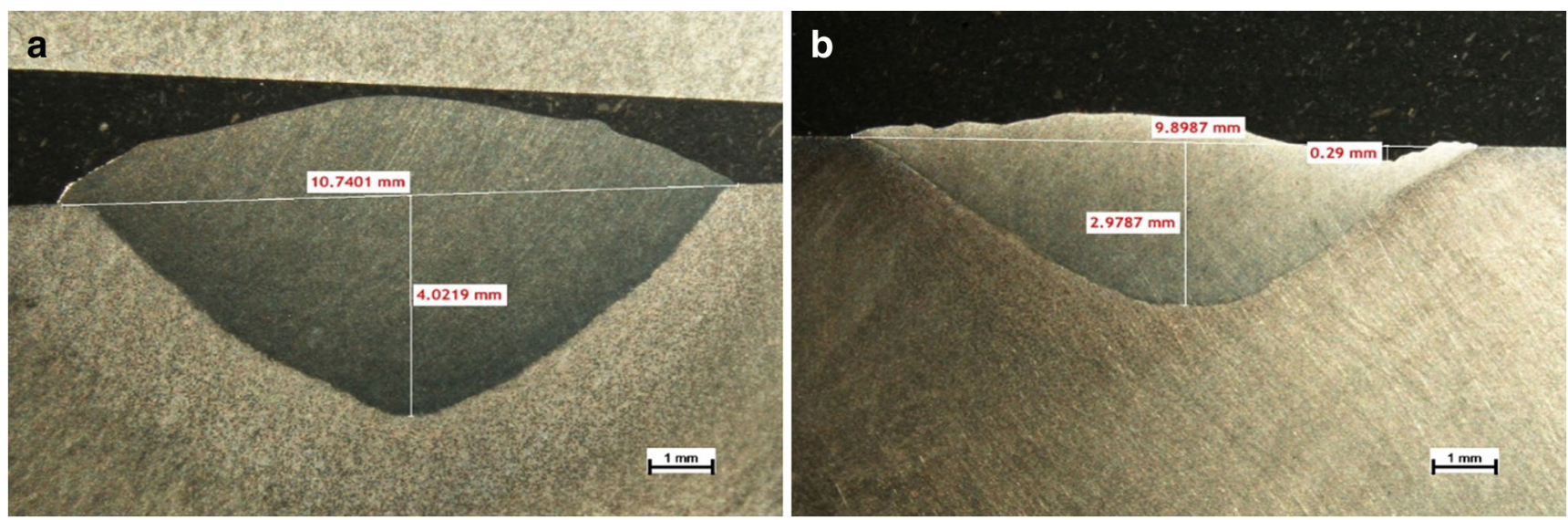

Fig. 2 CMT+P welds in ZE41A-T5 showing a a defect-free relatively deep penetration weld and $\mathbf{b}$ a relatively shallow weld with an underfill

The model for $Y_{1}$ explains $92.39 \%$ of variability in the data. At $95 \%$ confidence level, the linear sources $v$ (welding speed), $r$ (wire feed speed), and $p c$ (pulse correction factor) are significant. The quadratic (square) terms in the model for $Y_{1}$ are insignificant. ANOVA for $Y_{1}$ also suggests that the interaction sources are generally significant, although only $r^{*} p c$ has a $P$ value less than 0.05 . It was observed that the depth of penetration, $Y_{1}$, strongly depends on the linear sources and the interaction between the wire feed speed and the pulse correction factor.
In particular, the wire feed speed, $r$, has the most contribution to $Y_{1}$ in the $\mathrm{CMT}+\mathrm{P}$ process, accounting for $62.77 \%$ of the total contributions. According to the statistics, the lack-of-fit for $Y_{1}$ is insignificant but still contributes up to $6.39 \%$.

At 95\% confidence level, the linear sources $v$ and $r$ were found to be significant in the model for $Y_{2}$ (Table 4). Only one of the quadratic terms of $Y_{2}$, that is, $r^{2}$, was found to be significant. The interaction sources have minimal effect in the model for $Y_{2}$. We could say that the amount of underfill, $Y_{2}$,
Table 2 Design table for factors and responses of $\mathrm{CMT}+\mathrm{P}$ process

\begin{tabular}{|c|c|c|c|c|c|c|}
\hline \multirow[b]{2}{*}{$\begin{array}{l}\text { Run } \\
\text { order }\end{array}$} & \multirow[b]{2}{*}{$\begin{array}{l}\text { Standard } \\
\text { order }\end{array}$} & \multicolumn{3}{|c|}{ Process variables } & \multicolumn{2}{|c|}{ Output variables } \\
\hline & & $\begin{array}{l}\text { Travel speed, } v \\
(\mathrm{~mm} / \mathrm{s})\end{array}$ & $\begin{array}{l}\text { Wire feed rate, } r \\
(\mathrm{~m} / \mathrm{min})\end{array}$ & $\begin{array}{l}\text { Pulse corr. factor, } \\
p c \text { (unitless) }\end{array}$ & $\begin{array}{l}\text { Depth, } Y_{1} \\
(\mathrm{~mm})\end{array}$ & $\begin{array}{l}\text { Underfill, } \\
Y_{2}(\mathrm{~mm})\end{array}$ \\
\hline 1 & 7 & 9.6 & 14.4 & 3 & 4.35 & 0.00 \\
\hline 2 & 15 & 13.5 & 12.0 & 0 & 3.54 & 0.00 \\
\hline 3 & 3 & 9.6 & 14.4 & -3 & 3.79 & 0.00 \\
\hline 4 & 18 & 13.5 & 12.0 & 0 & 3.89 & 0.04 \\
\hline 5 & 13 & 13.5 & 12.0 & -5 & 3.07 & 0.10 \\
\hline 6 & 2 & 17.4 & 9.6 & -3 & 2.65 & 0.59 \\
\hline 7 & 14 & 13.5 & 12.0 & 5 & 3.66 & 0.25 \\
\hline 8 & 1 & 9.6 & 9.6 & -3 & 2.62 & 0.29 \\
\hline 9 & 10 & 20.0 & 12.0 & 0 & 3.08 & 0.52 \\
\hline 10 & 5 & 9.6 & 9.6 & 3 & 3.83 & 0.05 \\
\hline 11 & 6 & 17.4 & 9.6 & 3 & 3.46 & 0.36 \\
\hline 12 & 19 & 13.5 & 12.0 & 0 & 3.67 & 0.07 \\
\hline 13 & 20 & 13.5 & 12.0 & 0 & 3.66 & 0.00 \\
\hline 14 & 8 & 17.4 & 14.4 & 3 & 3.79 & 0.00 \\
\hline 15 & 9 & 7.0 & 12.0 & 0 & 3.73 & 0.00 \\
\hline 16 & 11 & 13.5 & 8.0 & 0 & 2.37 & 0.54 \\
\hline 17 & 12 & 13.5 & 16.0 & 0 & 4.58 & 0.12 \\
\hline 18 & 17 & 13.5 & 12.0 & 0 & 3.64 & 0.13 \\
\hline 19 & 4 & 17.4 & 14.4 & -3 & 3.96 & 0.31 \\
\hline 20 & 16 & 13.5 & 12.0 & 0 & 3.61 & 0.11 \\
\hline
\end{tabular}


Table 3 Analysis of variance (ANOVA) for response $Y_{1}$

\begin{tabular}{|c|c|c|c|c|c|c|c|}
\hline Source & & DF & SS & Contribution (\%) & MS & $F$ value & $P$ value \\
\hline \multirow[t]{13}{*}{ Model } & & 9 & 5.3342 & 92.39 & 0.5927 & 13.48 & 0.000 \\
\hline & Linear & 3 & 4.7119 & 81.61 & 1.5706 & 35.73 & 0.000 \\
\hline & $v$ & 1 & 0.2431 & 4.21 & 0.2431 & 5.53 & 0.041 \\
\hline & $r$ & 1 & 3.6245 & 62.77 & 3.6245 & 82.46 & 0.000 \\
\hline & $p c$ & 1 & 0.8443 & 14.62 & 0.8443 & 19.21 & 0.001 \\
\hline & Squares & 3 & 0.1275 & 2.21 & 0.0425 & 0.97 & 0.446 \\
\hline & $v^{2}$ & 1 & 0.0383 & 0.66 & 0.0536 & 1.22 & 0.296 \\
\hline & $r^{2}$ & 1 & 0.0117 & 0.20 & 0.0183 & 0.42 & 0.533 \\
\hline & $p c^{2}$ & 1 & 0.0775 & 1.34 & 0.0775 & 1.76 & 0.214 \\
\hline & Interaction & 3 & 0.4949 & 8.57 & 0.1650 & 3.75 & 0.049 \\
\hline & $v^{*} r$ & 1 & 0.0004 & 0.01 & 0.0004 & 0.01 & 0.926 \\
\hline & $v^{*} p c$ & 1 & 0.1596 & 2.76 & 0.1596 & 3.63 & 0.086 \\
\hline & $r^{*} p c$ & 1 & 0.3348 & 5.80 & 0.3348 & 7.62 & 0.020 \\
\hline \multirow[t]{3}{*}{ Error } & & 10 & 0.4395 & 7.61 & 0.0440 & & \\
\hline & Lack-of-fit & 5 & 0.3690 & 6.39 & 0.0738 & 5.23 & 0.047 \\
\hline & Pure error & 5 & 0.0706 & 1.22 & 0.0141 & & \\
\hline \multirow[t]{2}{*}{ Total } & & 19 & 5.7738 & 100.00 & & & \\
\hline & \multicolumn{5}{|c|}{$S=0.209653 R^{2}=92.39 \%$} & & \\
\hline
\end{tabular}

depends strongly on $v, r$, and $r^{2}$, with each accounting for $31.86 \%, 27.97 \%$, and $12.69 \%$ of the total contributions, respectively. The lack-of-fit contributed $13.49 \%$. The model for $Y_{2}$ accounts for $84.44 \%$ of the variability in the data.

Figure 3 shows the response surfaces for $Y_{1}$. As mentioned earlier, lower $v$ and higher $r$ have the effect of increasing the amount of energy deposited per unit length of the weld, consequently resulting in deeper penetration. Consistent with results from ANOVA, $r$ has the most effect in determining the depth of penetration during the $\mathrm{CMT}+\mathrm{P}$ welding. For a fixed value of $p c, Y_{1}$ changed significantly with $r$, compared with $v$. Similarly, for a fixed $v, Y_{1}$ changed significantly with $r$, compared with $p c$. The pulse correction factor, $p c$, also appears to have more significant effect on $Y_{1}$, compared with $v$. Overall,
Table 4 Analysis of variance (ANOVA) for response $Y_{2}$

\begin{tabular}{llrlcrrr}
\hline Source & & DF & SS & Contribution $(\%)$ & MS & $F$ value & $P$ value \\
\hline Model & & 9 & 0.628 & 84.44 & 0.070 & 6.03 & 0.005 \\
& Linear & 3 & 0.465 & 62.61 & 0.155 & 13.42 & 0.001 \\
& $v$ & 1 & 0.237 & 31.86 & 0.237 & 20.48 & 0.001 \\
& $r$ & 1 & 0.208 & 27.98 & 0.208 & 17.99 & 0.002 \\
& $p c$ & 1 & 0.021 & 2.76 & 0.021 & 1.78 & 0.212 \\
& Squares & 3 & 0.136 & 18.30 & 0.045 & 3.92 & 0.043 \\
& $v^{2}$ & 1 & 0.032 & 4.25 & 0.046 & 3.95 & 0.075 \\
& $r^{2}$ & 1 & 0.094 & 12.69 & 0.100 & 8.61 & 0.015 \\
& $p c^{2}$ & 1 & 0.010 & 1.37 & 0.010 & 0.88 & 0.371 \\
& Interaction & 3 & 0.026 & 3.53 & 0.009 & 0.76 & 0.544 \\
& $v^{*} r$ & 1 & 0.012 & 1.57 & 0.012 & 1.01 & 0.338 \\
& $v^{*} p c$ & 1 & 0.011 & 1.52 & 0.011 & 0.98 & 0.346 \\
& $r^{*} p c$ & 1 & 0.003 & 0.43 & 0.003 & 0.28 & 0.608 \\
Error & & 10 & 0.116 & 15.56 & 0.012 & & \\
& Lack-of-fit & 5 & 0.100 & 13.49 & 0.020 & 6.55 & 0.030 \\
& Pure error & 5 & 0.015 & 2.06 & 0.003 & & \\
& & 19 & 0.743 & 100.00 & & & \\
\end{tabular}



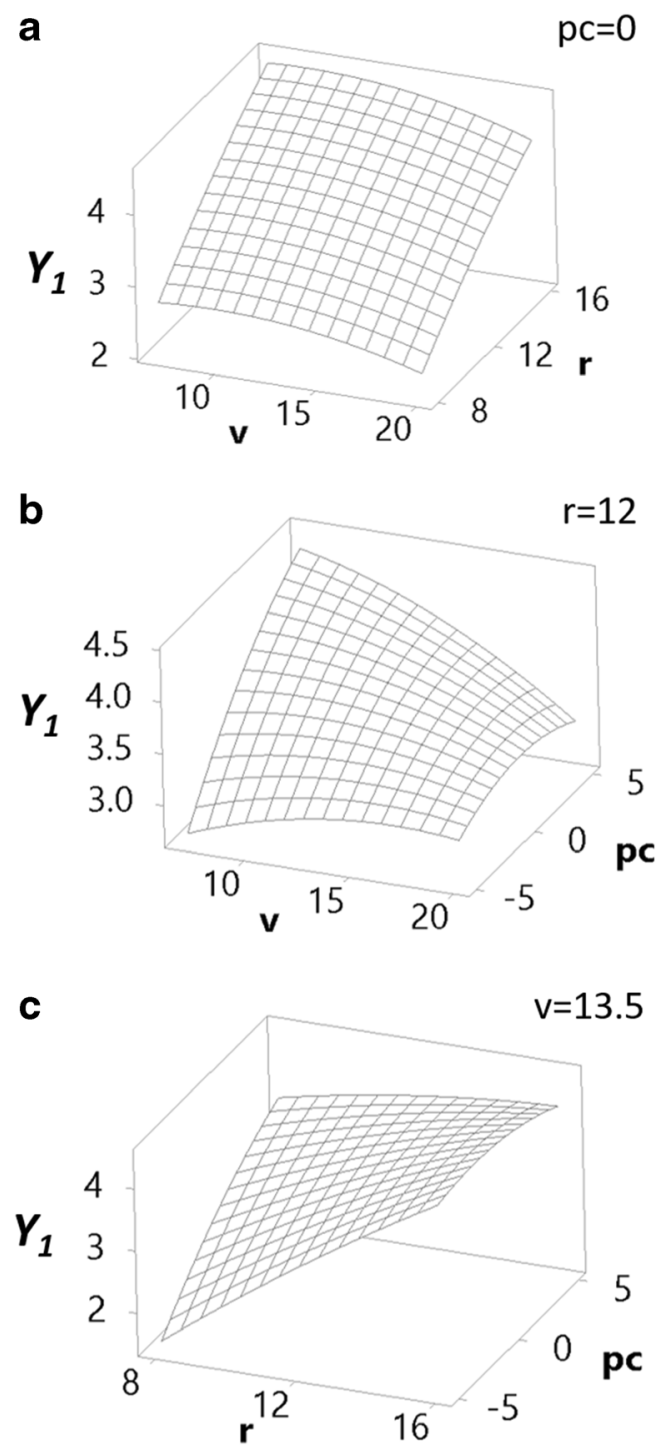

Fig. 3 Response surface plots of the CMT $+\mathrm{P}$ process for $Y_{l}$ a travel speed $(v)$ versus wire feed rate $(r)$ at pulse correction factor $(p c)=0, \mathbf{b}$ travel speed $(v)$ versus pulse correction factor $(p c)$ at wire feed rate $(r)=12 \mathrm{~m} /$ min, and $\mathbf{c}$ wire feed rate $(r)$ versus pulse correction factor $(p c)$ at travel speed $(v)=13.5 \mathrm{~mm} / \mathrm{s}$

Fig. 3 suggests somewhat minimal effect of curvature on the results. There was no minimum or maximum observed for either of the two output parameters.

The response surfaces for $Y_{2}$ (Fig. 4) reveal higher degrees of curvature. $Y_{2}$ has a minimum at a relatively higher value of the wire feed speed, $r$. Observation of changes in the direction of the value of an output parameter as a particular factor is monotonously changed has been regarded as one of the major achievements of DOE [18]. The response surfaces show that increasing $r$ would generally result in reduction of underfill. However, there is a value of $r$ (for a given set of other independent variables) at which this trend would reverse (Fig. $4 \mathrm{a}, \mathrm{c})$. The degree of curvature in $Y_{2}$ as a result of $v$ and $p c$ was not as prominent as that of $r$.

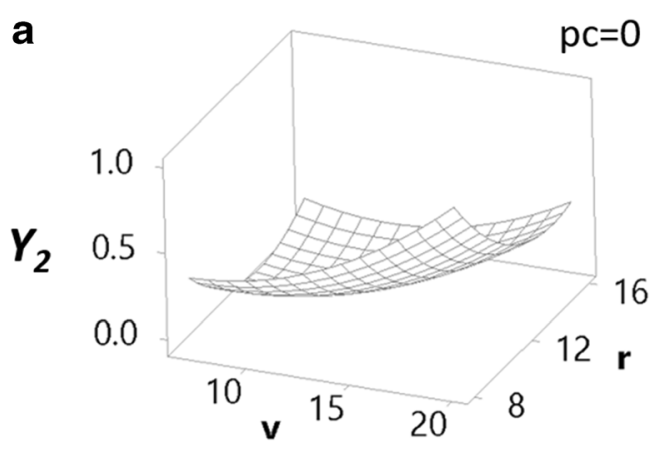

$\mathrm{pc}=0$

b
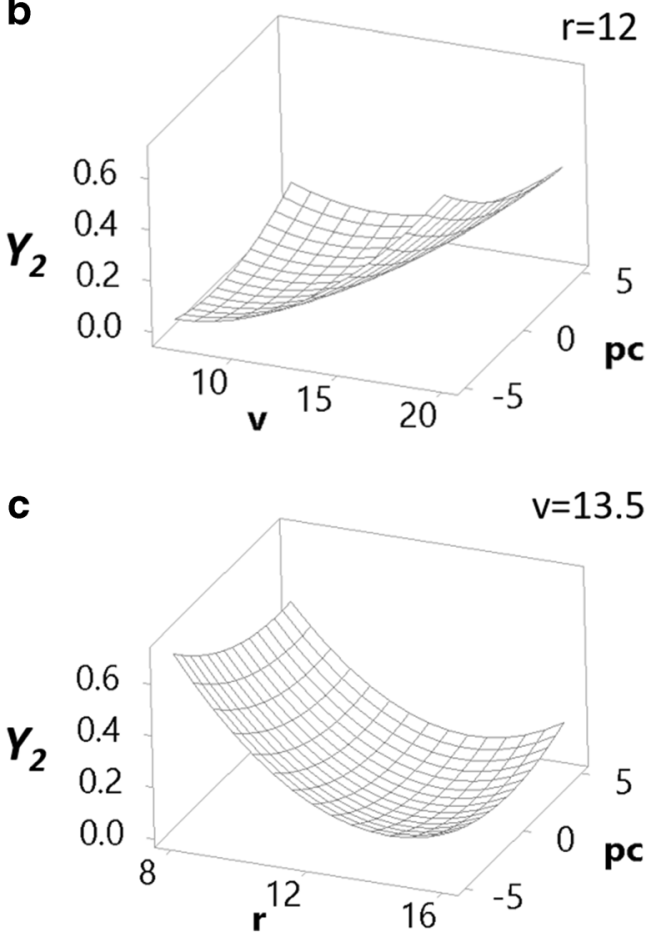

Fig. 4 Response surface plots of the CMT+P process for $Y_{2}$ a travel speed $(v)$ versus wire feed rate $(r)$ at pulse correction factor $(p c)=0, \mathbf{b}$ travel speed $(v)$ versus pulse correction factor $(p c)$ at wire feed rate $(r)=12 \mathrm{~m} /$ min, and $\mathbf{c}$ wire feed rate $(r)$ versus pulse correction factor $(p c)$ at travel speed $(v)=13.5 \mathrm{~mm} / \mathrm{s}$

\subsection{The CMT+P process optimization}

Process optimization involving an interest in multiple responses is known to be common for industry-based engineering problems [27]. The desirability function approach provides a flexible and robust optimization method for multiple

Table 5 Process optimization criteria

\begin{tabular}{clllll}
\hline Response & Goal & Lower & Target & Upper & Weight \\
\hline$Y_{1}$ & Target & 2.30 & 3.05 & 3.80 & 1 \\
$Y_{2}$ & Minimum & 0 & 0 & 0.76 & 1 \\
\hline
\end{tabular}


responses by using a dimensionless parameter as a measure of overall performance. The process for calculating this dimensionless composite desirability function was presented in Section 2.3.

Table 5 contains the criteria for process optimization. The goal was to set the response $Y_{1}$ at the target value while minimizing the response $Y_{2}$. The choice of the target goal for $Y_{1}$ was based on the aerospace application of interest and was specified by the repair development engineers, where a lower limit of $Y_{1}=2.30 \mathrm{~mm}$ was set to ensure adequate fusion of the weld with the base material. The target for $Y_{2}$ was set at zero (no defect is desirable), while the upper limit was set at $0.76 \mathrm{~mm}$ - the maximum allowable value based on AWS D17.1 class A standard.

Minitab 17 statistical analysis software was used to calculate the domain where a combination of the independent variables, $v, r$, and $p c$, satisfies the proposed optimization criteria. The individual desirability function, $d_{i}$ (obtained by transforming $Y_{i}$ using the conditions in Section 2.3), and the overall (composite) desirability function, $D$ (the geometric mean of Eq. 5), were calculated. Ten possible solutions were generated (Table 6). Solutions 1, 2, and 3 provide the highest composite desirability values. In fact, values of $D$ closer to 1 indicate how well the factor domain satisfies the optimization criteria. These results suggest that solutions 1, 2, and 3 with $D$ values of $0.9981,0.9955$, and 0.9763 , respectively, are the more optimal solutions.

In order to verify the reliability of the optimal solutions, a validation experiment was set up using the proposed factor domains in the solutions. It was determined that the factors in solutions 1 and 2 were very close. Two validation experiments were performed at the factor domains $v=7.0 \mathrm{~mm} / \mathrm{s}, r=$ $12.4 \mathrm{~m} / \mathrm{min}$, and $p c=-4.1$ and $v=7.0 \mathrm{~mm} / \mathrm{s}, r=13.0 \mathrm{~m} / \mathrm{min}$, and $p c=-5$, respectively. The results from the verification experiments are presented in Table 7 , showing the modeled and experimental output variables within the process optimization criteria.

Table 6 Factor domains, solutions, and resulting composite desirability, D

\begin{tabular}{cllllll}
\hline Solution & $v$ & $r$ & $p c$ & $Y_{1}$ & $Y_{2}$ & $D$ \\
\hline 1 & 7.00014 & 12.4203 & -4.09091 & 3.050 & 0.003 & 0.9981 \\
2 & 7.01108 & 12.5383 & -4.25564 & 3.054 & 0.003 & 0.9955 \\
3 & 7 & 13.0763 & -5 & 3.078 & 0.008 & 0.9763 \\
4 & 7.08987 & 8 & 1.1966 & 3.052 & 0.334 & 0.7481 \\
5 & 20 & 11.6086 & 5 & 3.051 & 0.373 & 0.7131 \\
6 & 20 & 11.4686 & 5 & 3.041 & 0.384 & 0.6992 \\
7 & 20 & 15.7424 & 5 & 3.241 & 0.309 & 0.6653 \\
8 & 20 & 15.826 & 5 & 3.242 & 0.313 & 0.6615 \\
9 & 18.1388 & 9.97588 & -5 & 2.326 & 0.750 & 0.0217 \\
\hline
\end{tabular}

Table 7 Results from verification experiments

\begin{tabular}{|c|c|c|c|c|c|c|c|}
\hline & \multicolumn{3}{|c|}{$\begin{array}{l}\text { Process } \\
\text { variables }\end{array}$} & \multicolumn{2}{|c|}{$\begin{array}{l}\text { Model predictions for } \\
\text { output variables }\end{array}$} & \multicolumn{2}{|c|}{$\begin{array}{l}\text { Experimental outpu } \\
\text { variables }\end{array}$} \\
\hline & $v$ & $r$ & $p c$ & Pred $Y_{1}$ & Pred $Y_{2}$ & Ave $Y_{1}$ & Ave $Y_{2}$ \\
\hline Exp 1 & 7.0 & 12.4 & -4.1 & 3.49 & 0.006 & 2.80 & 0.070 \\
\hline $\operatorname{Exp} 2$ & 7.0 & 13.0 & -5.0 & 3.51 & 0.012 & 3.19 & 0.030 \\
\hline
\end{tabular}

\section{Conclusions}

The pulsed cold metal transfer $(\mathrm{CMT}+\mathrm{P})$ process was evaluated for the repair of aerospace structural components made from ZE41A-T5 magnesium alloy. A rotatable 3D central composite design (CCD) was used to systematically establish relationships between independent welding variables and the resultant output variables of the $\mathrm{CMT}+\mathrm{P}$ process. A multiple response desirability function approach was then used for process optimization. The result can be summarized as follows:

1. The CMT+P process produced high-quality welds in the alloy. Welding process variables were established to produce desired weld penetration and weld reinforcement and complete fusion with minimal weld defects.

2. Mathematical models based on second-order polynomial and ANOVA were developed for the output (dependent) variables - depth of penetration, $Y_{1}$, and the amount of underfill, $Y_{2}$. The models substantially explained the variability in the experimental data and were useful for predicting the output variables with minimal errors.

3. Response surfaces revealed the degrees of curvature in the output variable data as the independent input variables were monotonously changed.

4. Optimal domains of the independent variables were achieved; where the welds comply with the applicationspecific (repair of gearbox housing) requirements and acceptable class A weld quality of the aerospace fusion welding standard AWS D17.1.

Acknowledgments The authors would like to thank Justin Grehan of Standard Aero for his technical expertise in CMT welding and for supporting the metallographic procedures.

Funding information This work was financially supported by the Consortium for Aerospace Research and Innovation in Canada (CARIC) and the industry partners - Standard Aero Limited and Huys Industries.

Open Access This article is distributed under the terms of the Creative Commons Attribution 4.0 International License (http:// creativecommons.org/licenses/by/4.0/), which permits unrestricted use, distribution, and reproduction in any medium, provided you give appropriate credit to the original author(s) and the source, provide a link to the Creative Commons license, and indicate if changes were made. 


\section{References}

1. Zhao M-C, Liu M, Song G-L, Atrens A (2008) Influence of microstructure on corrosion of as-cast ZE41. Adv Eng Mater 10(1-2): 104-111

2. Smola B, Stulikova I, Von Buch F, Mordike BL (2002) Structural aspects of high performance $\mathrm{Mg}$ alloys design. Mater Sci Eng A 324(1):113-117

3. Singh Raman RK (2004) The role of microstructure in localized corrosion of magnesium alloys. Metall Mater Trans A 35A(8): 2525-2531

4. Lorenzin G, Rutili G (2009) The innovative use of low heat input in welding: experiences on 'cladding' and brazing using the CMT process. Weld Int 23(8):622-632

5. Pickin CG, Williams SW, Lunt M (2011) Characterisation of the cold metal transfer (CMT) process and its application for low dilution cladding. J Mater Process Technol 211:496-502

6. Zhang HT, Feng JC, He P, Zhang BB, Chen JM, Wang L (2009) The arc characteristics and metal transfer behaviour of cold metal transfer and its use in joining aluminium to zinc-coated steel. Mater Sci Eng A 499:111-113

7. Egerland S, Helmholdt R 2008 Overlaying (cladding) of high temperature affected components by using cold metal transfer process. Proceedings of the IIW 2008 international conference on safety and reliability of welded components in energy and processing industry, Graz, Austria, July 2008, paper CL-5

8. Wang J, Feng JC, Wang YX (2008) Microstructure of Al-Mg dissimilar weld made by cold metal transfer MIG welding. Mater Sci Technol 24(7):827-831

9. Ahmad R, Bakar MA (2011) Effect of a post-weld heat treatment on the mechanical and microstructure properties of AA6061 joints welded by the gas metal arc welding cold metal transfer method. Mater Des 32:5120-5126

10. Cao R, Wang T, Wang C, Feng Z, Lin Q, Chen JH (2014) Cold metal transfer welding-brazing of pure titanium TA2 to magnesium alloy AZ31B. J Alloys Compd 605(25):12-20

11. Sequeira Almeida PM, Williams S 2009 Innovative process model of Ti-6Al-4V additive layer manufacturing using cold metal transfer (CMT), Dec. 2009, Proceedings of the 21st annual international solid freeform fabrication symposium, 25-36

12. Baoqiang Cong, Zewu Qi, Bojin Qi, Hongye Sun, Gang Zhao and Jialuo Ding 2017 A comparative study of additively manufactured thin wall and block structure with $\mathrm{Al}-6.3 \% \mathrm{Cu}$ alloy using cold metal transfer process. Applied Sciences 7 (3): article number 275

13. Gomez AO, Galvan LC, Deschaux-Beaume F, Mezrag B, Rouquette S (2017) Effect of process parameters on the quality of aluminium alloy $\mathrm{A} 15 \mathrm{Si}$ deposits in wire and arc additive manufacturing using a cold metal transfer process. Sci Technol Weld Join 23(4):316-332

14. Prado-Cerqueira JL, Diéguez JL, Camacho AM (2017) Preliminary development of a wire and arc additive manufacturing system (WAAM). Procedia Manufacturing 13:895-902
15. Campana G, Fortunato A, Ascari A, Tani G, Tomesani L (2007) Influence of arc transfer mode in hybrid laser-MIG welding. J Mater Process Technol 191:111-113

16. Kim IS, Son KJ, Yang YS, Yaragada PKDV (2003) Sensitivity analysis for process parameters in GMA welding processes using a factorial design method. Int J Mach Tools Manuf 43:763-769

17. Ola OT, Doern FE 2013 Understanding the effect of welding parameters in laser-GMA hybrid welding of an aluminum alloy using full factorial design, materials science and technology (MS\&T), Light Metals for Transportation, Montreal, pp 1363-1374

18. Moradi M, Salimi N, Ghoreishi M, Abdollahi H, Shamsborhan M, Frostevarg J, Liar T, Kaplan AFH (2014) Parameter dependencies in laser hybrid arc welding by design of experiments and by a mass balance. J. Laser Appl. 26(2):022004-1-022004-9

19. Benyounis KY, Olabi AG, Hashmy MSJ (2008) Multi-response optimization of $\mathrm{CO} 2$ laser-welding process of austenitic stainless steel. Opt Laser Technol 40:76-87

20. Suthakar T, Balasubramanian KR, Sankaranarayanasamy K 2012 Multi objective optimization of laser welding process parameters by desirability approach of design of experiments. Proceedings of the ASME 2012 International Mechanical Engineering Congress \& Exposition IMECE2012-86782, November 9-15, 2012, Houston, Texas, USA, pp. 1921-1929

21. Jing Wang, Zhen He, Jin-Ho Oh, Sung-Hyun Park 2008 Multiresponse robust optimization using desirability function. 2008 IEEE Symposium on Advanced Management of Information for Globalized Enterprises (AMIGE), 28-29 Sept. 2008, Tianjin, China, pp 1-3

22. Kim HR and Lee YC 2008 Using the orthogonal array with grey relational analysis to optimize the laser hybrid welding of a 6061T6 Al alloy sheet. Proc. IMechE Vol. 222 Part B: J. Engineering Manufacture, 2008, pp. 981-987

23. Oluwasegun KM, Ojo OA, Ola OT, Birur A, Cuddy J, Chan K (2018) Development of artificial neural network models for predicting weld output parameters in advanced fusion welding of a magnesium alloy. Am J Model Optim 6(1):18-34

24. Park H, Rhee S (1999) Estimation of weld bead size in CO2 laser welding by using multiple regression and neural network. J Laser Appl 11(3):143-150

25. Derringer G, Suich R (1980) Simultaneous optimization of several response variables. J Qual Technol 12(4):214-219

26. Fronius CMT 4000 Advanced Operating Instruction Manual 42, 0426,0001, EN 006-04092012

27. Korra NN, Vasudevan M, Balasubramanian KR (2015) Multiobjective optimization of activated tungsten inert gas welding of duplex stainless steel using response surface methodology. Int $\mathbf{J}$ Adv Manuf Technol 77:67-81

Publisher's note Springer Nature remains neutral with regard to jurisdictional claims in published maps and institutional affiliations. 